\title{
Correction: Huet, R.; Johanson, G. 1,1-Difluoroethane Detection Time in Blood after Inhalation Abuse Estimated by Monte Carlo PBPK Modeling. Pharmaceutics 2020, 12, 997
}

\author{
Raul Huet ${ }^{1,2}$ (D) and Gunnar Johanson ${ }^{3, *} \mathbb{D}$ \\ 1 Department of Psychiatry, Volunteer Faculty, University of Missouri-Kansas City School of Medicine, \\ 2411 Holmes Street, Kansas City, MO 64110, USA; rahuet@sbcglobal.net \\ 2 Department of Psychiatry, Volunteer Faculty, University of Kansas School of Medicine, 3901 Rainbow Blvd., \\ Kansas City, KS 66160, USA \\ 3 Toxicology and Risk Assessment, Integrative Toxicology, Institute of Environmental Medicine, Karolinska \\ Institutet, Box 210, SE-17177 Stockholm, Sweden \\ * Correspondence: gunnar.johanson@ki.se; Tel.: +46-70-777-5504
}

Citation: Huet, R.; Johanson, G. Correction: Huet, R.; Johanson, G 1,1-Difluoroethane Detection Time in Blood after Inhalation Abuse Estimated by Monte Carlo PBPK Modeling. Pharmaceutics 2020, 12, 997. Pharmaceutics 2021, 13, 1037. https:// doi.org/10.3390/pharmaceutics 13071037

Received: 22 June 2021

Accepted: 28 June 2021

Published: 7 July 2021

Publisher's Note: MDPI stays neutral with regard to jurisdictional claims in published maps and institutional affiliations.

Copyright: (C) 2021 by the authors Licensee MDPI, Basel, Switzerland. This article is an open access article distributed under the terms and conditions of the Creative Commons Attribution (CC BY) license (https:/ / creativecommons.org/licenses/by/ $4.0 /)$.
The authors wish to make the following corrections to this paper [1]:

Text Correction

There was an error in the original article in the Abstract section: "(3) Results: With a detection limit of $0.14 \mathrm{mg} / \mathrm{L}$, the median MDT was estimated to be $10.5 \mathrm{~h}$ (5th-95th percentile 7.8-12.8 h) after the 2-h abuse scenario and $13.5 \mathrm{~h}(10.5-15.8)$ after the 6-h scenario. The ranges reflect variability in body mass index and hence amount of body fat; (4) Conclusions: Our simulations suggest that the MDT of difluoroethane in blood after abuse ranges from 7.8 to $15.8 \mathrm{h."}$

A correction has been made to the Abstract section: "(3) Results: With a detection limit of $0.14 \mathrm{mg} / \mathrm{L}$, the median MDT was estimated to be $10.5 \mathrm{~h}$ (5th-95th percentile 7.8-12.8 $\mathrm{h}$ ) after the 2-h abuse scenario and $9.5 \mathrm{~h}(6.5-11.8 \mathrm{~h})$ after the 6-h scenario. The ranges reflect variability in body mass index (and, hence, amount of body fat) and, more so, variable inhalation patterns; (4) Conclusions: Our simulations suggest that the MDT of difluoroethane in blood after abuse ranges from 6.5 to $12.8 \mathrm{~h} . "$

Text Correction

There was an error in the original article in the Results section in Paragraph 4: "Thus, the median of the MDT ranges widely, from $2.0 \mathrm{~h}$ for the shorter exposure scenario $(\mathrm{Y})$ with the highest detection limit, to $18.7 \mathrm{~h}$ for the longer exposure scenario $(\mathrm{X})$ with the lowest detection limit."

A correction has been made to the Results section in Paragraph 4: "Thus, the median of the MDT ranges widely, from $1.2 \mathrm{~h}$ for the highest detection limit (scenario $\mathrm{X}$ ) to $15.7 \mathrm{~h}$ for the lowest detection limit (scenario Y)."

Error in Table

In the original article there was a mistake in Table 4 as published:

Table 4. Predicted maximum detection times of DFE in blood for different detection limits and the two exposure scenarios.

\begin{tabular}{cccc}
\hline $\begin{array}{c}\text { Detection Limit } \\
(\mathbf{m g} / \text { L Blood })\end{array}$ & Scenario & \multicolumn{2}{c}{ Maximum Detection Time from End of Abuse Session (h) } \\
\cline { 2 - 4 } & $\mathrm{X}$ & Median & 5th-95th Percentile \\
\hline \multirow{2}{*}{0.018} & $\mathrm{Y}$ & 18.7 & $15.0-21.5$ \\
\cline { 2 - 4 } & $\mathrm{X}$ & 15.7 & $12.0-18.3$ \\
\hline \multirow{2}{*}{0.14} & $\mathrm{Y}$ & 13.5 & $10.5-15.8$ \\
\hline
\end{tabular}


Table 4. Cont.

\begin{tabular}{cccc}
\hline $\begin{array}{c}\text { Detection Limit } \\
(\mathbf{m g} / \text { L Blood })\end{array}$ & Scenario & \multicolumn{2}{c}{ Maximum Detection Time from End of Abuse Session (h) } \\
\cline { 2 - 4 } & $\mathrm{X}$ & Median & 5th-95th Percentile \\
\hline \multirow{2}{*}{5.4} & $\mathrm{Y}$ & 5.2 & $4.3-6.3$ \\
\cline { 2 - 4 } & & 2.0 & $1.0-3.3$ \\
\hline
\end{tabular}

The corrected Table 4 appears below:

Table 4. Predicted maximum detection times of DFE in blood for different detection limits and the two exposure scenarios.

\begin{tabular}{cccc}
\hline $\begin{array}{c}\text { Detection Limit } \\
\text { (mg/L Blood) }\end{array}$ & Scenario & \multicolumn{2}{c}{ Maximum Detection Time from End of Abuse Session (h) } \\
\cline { 2 - 4 } 0.018 & $\mathrm{X}$ & Median & 5th-95th Percentile \\
\cline { 2 - 4 } & $\mathrm{Y}$ & 14.7 & $11.0-17.5$ \\
\hline \multirow{2}{*}{0.14} & $\mathrm{X}$ & 15.7 & $12.0-18.3$ \\
\cline { 2 - 4 } & $\mathrm{Y}$ & 9.5 & $6.5-11.8$ \\
\hline \multirow{2}{*}{5.4} & $\mathrm{X}$ & 10.5 & $7.8-12.8$ \\
\cline { 2 - 4 } & $\mathrm{Y}$ & 1.2 & $0.3-2.3$ \\
\hline
\end{tabular}

\section{Text Correction}

There was an error in the original article in the Discussion section in Paragraph 1: "With a detection limit (LOQ) of $0.14 \mathrm{mg} / \mathrm{L}$, the predicted median MDT is $13.5 \mathrm{~h}$ after the 6 $\mathrm{h}$ abuse scenario and $10.5 \mathrm{~h}$ after the $2 \mathrm{~h}$ abuse scenario."

A correction has been made to the Discussion section in Paragraph 1: "With a detection limit (LOQ) of $0.14 \mathrm{mg} / \mathrm{L}$, the predicted median MDT is $9.5 \mathrm{~h}$ after the $6 \mathrm{~h}$ abuse scenario and $10.5 \mathrm{~h}$ after the $2 \mathrm{~h}$ abuse scenario."

Text Correction

There was an error in the original article in the Discussion section in Paragraph 6: "In conclusion, using PBPK modeling and Monte Carlo simulation, we estimate that the MDT of DFE in blood after abuse is on the order of hours, sufficient to allow testing for it even up to $8-16 \mathrm{~h}$ after suspected intoxication."

A correction has been made to the Discussion section in Paragraph 6: "In conclusion, using PBPK modeling and Monte Carlo simulation, we estimate that the MDT of DFE in blood after abuse is on the order of hours, sufficient to allow testing for it even up to 7-13 h after suspected intoxication."

The authors would like to apologize for any inconvenience caused to the readers by these changes.

Conflicts of Interest: The authors declare no conflict of interest.

\section{Reference}

1. Huet, R.; Johanson, G. 1,1-Difluoroethane Detection Time in Blood after Inhalation Abuse Estimated by Monte Carlo PBPK Modeling. Pharmaceutics 2020, 12, 997; Erratum in 2021, 13, 50. [CrossRef] [PubMed] 